\title{
Silla turca vacía e hipopituitarismo.
}

\author{
NECOCHEA Yngrid *, LOJA David **, AVILES Roberto *, VILCA Maricela ***
}

\section{SUMMARY}

We present the case of a multiparous and obese woman of 59 years with partial hypopituitarism having an empty sella syndrome. We describe the clinical, radiological and biochemical findings. The diagnosis of empty sella was confirmed by computarized tomography. The levels of thyroxine, cortisol and growth hormone were decreased, with pituitary hyporresponsiveness to hypoglicemia induced with insulin. The replacement therapy was successful. ( Rev Med Hered 1998; 9:84-88).

\section{KEY WORDS: Empty sella turcica, computarized tomography, partial hypopituitarism.}

\section{INTRODUCCIÓN}

Se denomina síndrome silla turca vacía (SSTV) al aumento de tamaño con atrofia de la adenohipófisis y acumulación de líquido cefalorraquídeo dentro de la fosa pituitaria. Radiológicamente se observa ensanchamiento selar simétrico con retrodesplazamiento de las clinoides. El cuadro clínico puede estar relacionada con luxación del quiasma óptico, fístula del líquido cefalorraquídeo e hipopituitarismo parcial o total $(1,2,3)$. También pueden haber casos asintomáticos, por lo que algunos autores prefieren llamar silla turca vacía al hallazgo radiográfico de ésta en un paciente sin síntomas y reservar el término de síndrome de silla turca vacía para los que presentan la alteración radiográfica con cuadro clínico sugestivo de enfermedad selar (4).

Se considera síndrome de silla turca vacía primario (SSTVP) cuando se excluye tumor hipofisiario, independientemente del tamaño y del tratamiento recibido, y se descarta cualquier proceso intracraneal que eleve la presión intracraneal $(1,4,5,6)$.
La disfunción hipofisiaria en el SSTVP suele ser relativamente infrecuente, en el rango de 5$10 \%$ de los casos, lo cual motiva la presentación de nuestro caso.

\section{Caso clínico}

Paciente mujer de 59 años de edad, iletrada, natural de Huancavelica y procedente de Lima que ingresó al hospital con una historia de 3 años de evolución caracterizado por intolerancia al frío, mareos, palidez, y sensación de desvanecimiento, que se exacerbaban en invierno. Aproximadamente 7 meses antes del ingreso, se agregaron constipación, astenia, fatigabilidad con actividades cotidianas, balonamiento abdominal, meteorismo y reflujo gastroesofágico. Un mes antes los familiares la notaron con bradilália, con la voz apagada, tendencia al sueño y con dolor abdominal inespecífico. Tenía como antecedentes 11 gestaciones. Dio de lactar a todos sus hijos y posteriormente tuvo menstruaciones normales. El último hijo lactó hasta los 2 años de edad. Su último parto fue hace 22 años, aparentemente no hubo sangrado masivo y su última regla aproximadamente 2-3 años después.

\footnotetext{
* Médico cirujano. SERUMS.

** Médico Asistente. Departamento de Medicina, Hospital Arzobispo Loayza.

*** Médico cirujano. Instituto Peruano de Seguridad Social.
} 
El examen físico reveló: PA 100/60 mmHg. FC 71x' FR 15x' Temperatura oral $36^{\circ} \mathrm{C}$. Obesa, orientada, piel pálida, fría, seca, madarosis bilateral, vello axilar y pubiano disminuidos, uñas con tendencia a la coiloniquia, no edemas, macroglosia y halitosis. No se palpaba tiroides. El examen del tórax era negativo. Los ruidos cardíacos eran rítmicos y de intensidad disminuida y se auscultaron soplos. El abdomen era globuloso, con múltiples estrías atróficas. El examen neurológico mostró bradipsiquia, bradilalia, hiporreflexia osteotendinosa con fase de relajación lenta.

Los exámenes de laboratorio mostraron: Hematocrito 25\%, hemoglobina $9.40 \mathrm{gr} / \mathrm{dl}$, Leucocitos 3800 A:2 S:57 E:7 B:0 M:3, L:31, hipocromía, microcitosis. Plaquetas 175,000. Velocidad de sedimentación: $54 \mathrm{~mm} / \mathrm{h}$ (Wintrobe). Glicemia $85 \mathrm{mg} / \mathrm{dl}$. Creatinina $1.12 \mathrm{mg} / \mathrm{dl}$. El examen coproparasitológico seriado fue negativo. TSH: $1.4 \mathrm{Mui} / \mathrm{ml}$ (0.3-6.0), $\mathrm{T}_{3}: 31 \mathrm{ng} / \mathrm{dl}$ (70-200), $\mathrm{T}_{4}: 1.5 \mathrm{Eg} / \mathrm{dl}$ (4.2-12.5), prolactina: $1.0 \mathrm{ng} / \mathrm{ml}(0-25)$, cortisol matutino $1.15 \mathrm{ug} / \mathrm{dl}$ (5-25).

La prueba de estimulación con insulina mostró el siguiente resultado: Hormona de crecimiento $(\mathrm{ng} / \mathrm{dl})<1$, en el basal, a los 15, 30, 60 y 75 minutos y cortisol ( $\mathrm{Gg} / \mathrm{dl}), 2.9,3.0,3.0$, 4.4 y 4.0 en el control basal y a los $15,30,60$ y 75 minutos, respectivamente.

En el electrocardiograma se entraron complejos de bajo voltaje en derivaciones precordiales y derivaciones de miembros, las ondas $\mathrm{T}$ negativas y simétricas en $\mathrm{V} 1-\mathrm{V} 3, \mathrm{~T}$ aplanadas en forma difusa.

La ecografía abdominal mostró el hígado aumentado de volumen y ecogenicidad. Mientras que en la radiografía de silla turca, agrandamiento y balonamiento de la silla turca con adelgazamiento de paredes con relación a proceso intraselar.

En la TAC cerebral se encontró contenido hipodenso y homogéneo de la región intraselar con aspecto filiforme del tallo hipofisiario; sin observarse glándula hipófisis con sus características habituales. El volumen de la silla turca se encuentra incrementado sin alteraciones del piso o dorso. (Ver fotografías $\mathrm{N}^{\circ} 1 \mathrm{y} \mathrm{N}^{\circ} 2$ ).

La paciente recibió tratamiento con prednisona y levotiroxina. En el seguimiento ambulatorio no refirió

síntomas y los signos clínicos característicos pertinentes han disminuido.

\section{DISCUSIÓN}

El hipopituitarismo es el resultado de la disminución en la secreción de una, varias o todas las hormonas hipofisiarias, constituyendo una deficiencia selectiva parcial o total respectivamente. Una causa común de hipopituitarismo son los tumores intraselares o paraselares, como los adenomas hipofisiarios, los craneofaringiomas, meningiomas y linfomas. La necrosis isquémica de la hipófisis, posterior a una hemorragia post parto así como la isquemia hipofisiaria por vasculitis o por diabetes mellitus pueden ocasionar pérdida de la función hipofisiaria. El hipopituitarismo puede presentarse por infección de la de la hipófisis producida por tuberculosis, brucellosis, sífilis, micosis; o por otras enfermedades tales como: sarcoidosis, hemocromatosis e histiocitosis; así mismo por irradiación, hipofisectomía, trauma cefálico, hipofísitis autoinmune y el síndrome de silla turca vacía $(1,7,8,9,10,11)$.

El diagnóstico de silla turca vacía primaria, antes de la aparición de la tomografía computarizada (TAC) y de la resonancia magnética nuclear (RMN), se establecía evidenciando la presencia de aire en la silla turca en la neumoencefalografía $(1,2,3)$. Actualmente, sea en la TAC o en la RMN, se requiere la entrada del contraste dentro de la silla turca para el diagnostico y para excluir la posibilidad de un tumor quístico debe apreciarse el infundíbulo conectando directamente la glándula pituitaria residual con el hipotálamo $(7,8)$.

Los estudios de necropsia señalan una incidencia de SSTVP que varían de 5.5 a $23.5 \%(1,3,9)$. Cuando se evalúan niños $\mathrm{y}$ adolescentes por insuficiencia adenohipofisiaria la incidencia del SSTVP alcanza el 10.9\%; otros autores encuentran hasta $58 \%$ (12).

El SSTVP se presenta más frecuentemente en mujeres que en varones con una relación 16:1, probablemente debido a la hipertrofia hipofisiaria secundaria al embarazo (4); siendo más común en la quinta década de la vida, en obesas y multíparas, características que reúne el presente caso. También está descrita su asociación con cefalea, hipertensión arterial, alteraciones visuales, galactorrea, amenorrea, pseudotumor cerebral, hidrocefalia $(1,3,4,13,14,15)$. 


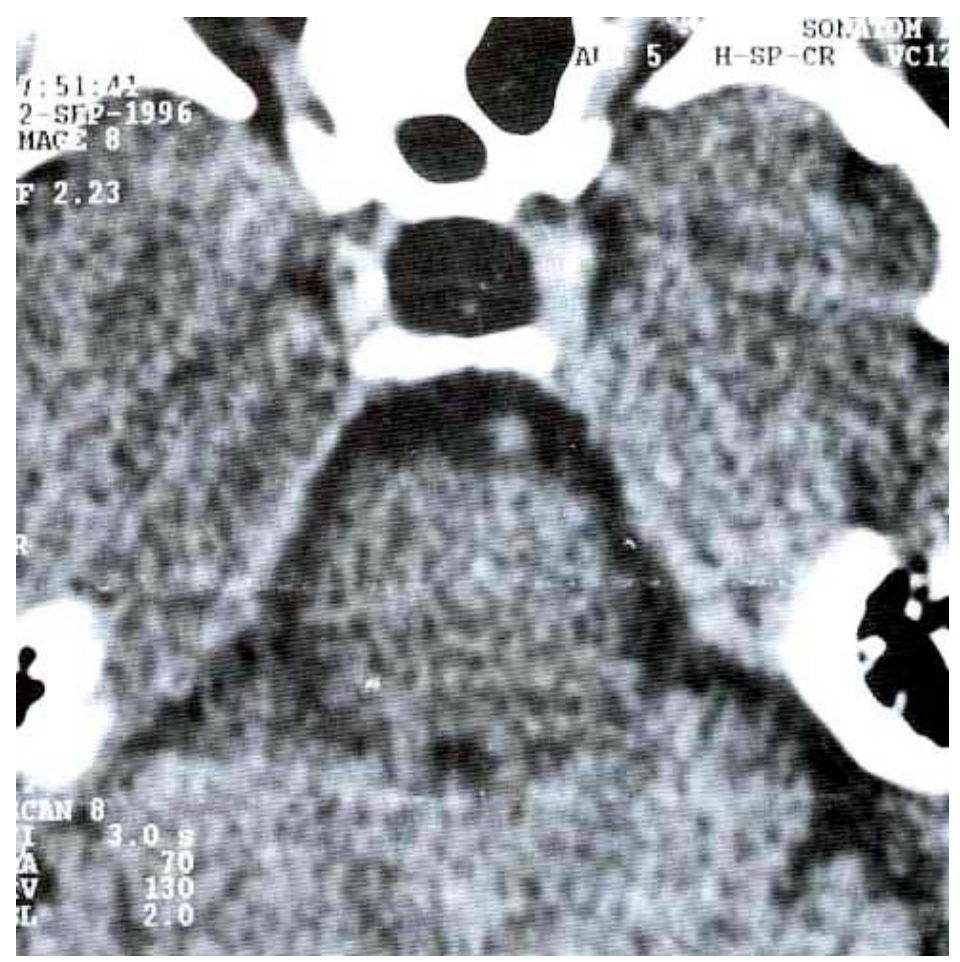

Foto $\mathbf{N}^{\circ} 1$

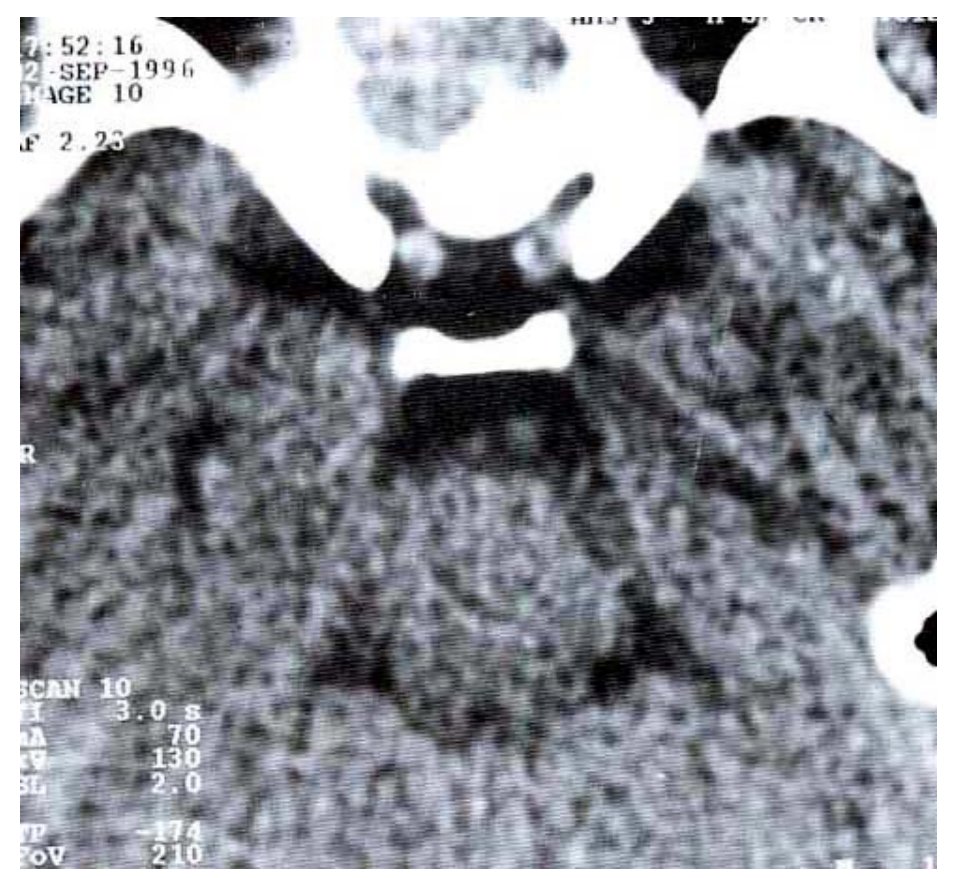

Foto $\mathrm{N}^{\circ} 2$

Rev Med Hered 9(2), 199886 
En la mayoría de las series la función hipofisiaria en SSTVP se conserva normal, sin embargo, cuando se utilizan pruebas dinámicas, se detecta disfunción en el $30 \%(3,4,9)$.

Las alteraciones funcionales son en muchas ocasiones más selectivas que globales. Se han descrito cuadros de hiperfunción y de hipofunción hormonal como acromegalia, enfermedad de Cushing, galactorrea-amenorrea y más frecuentemente ausencia de respuesta de la hormona de crecimiento ante pruebas de estimulación, déficit aislado de ACTH, pobre respuesta de TSH a TRH con o sin hipotiroidismo secundario asociado, hipogonadismo, diabetes insípida y panhipopituitarismo $(3,4)$.

La evaluación inicial del hipopituitarismo incluye la determinación del tenor de cortisol matutino, tiroxina, estradiol, testosterona, ACTH, TSH, FSH/LH, somatotrofina, prolactina. En la insuficiencia secundaria o terciaria, los niveles hormonales hipofisiarios son bajos o "normales". Eventualmente es necesario determinar el grado de reserva hipofisiaria con pruebas como la de hipoglicemia inducida por insulina que evalúa la reserva de somatotropina, ACTH y prolactina, la prueba de la metirapone que evalúa la integridad del eje hipotálamohipófisis-suprarrenal, la prueba de TRH que se utiliza para diferenciar entre el hipotiroidismo hipofisiario y el de origen hipotalámico y la prueba de $\mathrm{Gn}-\mathrm{Rh}$ que analiza el eje hipotálamo-hipófisis-ovario.

En nuestra paciente el primer eje comprometido fue el del hipotálamo-hipófisis-tiroides en la que fue evidente un cuadro clínico muy florido de hipotiroidismo que correlacionó con niveles inapropiados de tiroxina y triyodotironina para el nivel de tirotropina mostrado, lo que excluye enfermedad primaria de la glándula tiroidea. No fue posible efectuar el test de estimulación con TRH. Es inusual observar hipotiroidismo clínico manifiesto en los casos secundarios, puesto que las manifestaciones severas de hipotiroidismo secundarios son excepcionales (5).

En la prueba de tolerancia a la insulina, la hipoglucemia inducida por la insulina, en un sujeto eleva el nivel de ACTH y el cortisol. La respuesta plasmática normal de la somatotrofina es una elevación hasta por lo menos 7-9 ng/ml y el cortisol plasmático normalmente se eleva $10 \mathrm{ug} / \mathrm{dl} \mathrm{o}$ más sobre el nivel basal o alcanza un valor total de $20 \mathrm{ug} / \mathrm{dl}$ o más. En nuestro caso demostramos ausencia de la reserva de somatotrofina y corticotrofina. Se inició terapia de reemplazo hormonal con levotiroxina y prednisona, la evolución fue satisfactoria y en el seguimiento 12 meses después está asintomática.
El manejo quirúrgico es motivo de controversia. Gallardo, sugiere una cuidadosa evaluación de cada caso y sólo se debe considerar el tratamiento quirúrgico si existieran rinorraquia, cefalea incapacitante o defectos en los campos visuales. La indicación de cirugía descompresiva, para Montaban, se limita a los casos de severa pérdida de visión o de conciencia o de evolución tórpida; mientras que Vásquez y col. plantean la corrección quirúrgica una vez establecido el diagnóstico antes que aparezcan signos neurooftalmológicos (2,6,16). Creemos que los casos complejos ameritan una evaluación individual y la decisión debería ser en conjunto por el clínico, oftalmólogo y el neurocirujano.

\section{Correspondencia:}

David Loja Oropeza

Departamento de Medicina, Hospital Nacional Arzobispo Loayza.

Av. Alfonso Ugarte 848. Lima, Perú.

\section{BIBLIOGRAFÍA}

1. Berke J., Buxton L., Kokmen E. The empty sella. Neurology 1975; 25: 1137-1143.

2. Vásquez C., Alger M., Cabrera V. y col. Evolución de la deficiencia hipofisiaria después de corrección quirúrgica del síndrome de silla turca vacía Rev Invest Clin 1981; 33: 205208.

3. Miranda R., Vásquez C., Chávez M. y col. Análisis clínico y de la función hipofisiaria en pacientes con el síndrome de la silla turca vacía primaria. Arch Invest Med 1987; 18: 261-266.

4. Hung S., Guarnaluse R., Vásquez R. y col. Síndrome de la silla turca vacía primaria: valoración evolutiva clínica, bioquímica y radiológica. Rev Cub Med 1991; 30(2): 11-25.

5. Pizarro A., Ruiz-Giardin J., LaHulla F. y col. Hipotiroidismo secundario aislado asociado a silla turca vacía. Endocrinología 1996; 43(3): 82-84.

6. Fernández-Real J., Ricart W. Valor fisiológico y patológico de la silla turca vacía. Endocrinología 1996; 43(5): 131-132. 
7. Melded S. Tumor mass effects of lesion in the hypothalamus and pituitary in Endocrinology De Groot L. Third Edition. W.B. Saunders Company. 1995; 458-466.

8. Witte R., Mark L., Daniels D. et al. Radiographic evaluation of the pituitary and anterior hypothalamus. IN: Endocrinology Ce Groot L. Third Edition. W.B. Saunders Company. 1995; 467-486.

9. Jordan R., Kendall J., Kerber Ch. The primary empty sella syndrome. Am J Med 1977; 62: 569-580.

10. Mau M, Phillips T., Ratner R. Presence of antipituitary hormone antibodies in patients with empty sella syndrome and pituitary tumours. Clin Endocrinol 1993; 38: 495-500.

11. Hernández A., Raquel J. Hipofisítis linfocítica. Rev Cub Endocrinol 1995; 6: 118-126.
12. Cacciari E., Zucchini S., Ambrosetto P. Empty sella in children and adolescents with possible hypothalamic-pituitari disorders. J Clin Endocrinol Metab 1994; 78: 767-771.

13. Komatsu M., Kondo T., Yamauchi K. et al. Antipituari antibodies in patients with the primary empty sella syndrome. J Clin Endocrinol Metab 1988; 67:633-638.

14. Gallardo E., Schachter OM, Cáceres E. The empty sella: Results of treatment in 76 successive cases and high frequency of endocrine and neurological disturbances. Clin Endocrinol 1992; 37: 529-533.

15. Ferreira T., Vaisman M, Buescu A. et al. Twentythree cases of empty sella syndrome. Rev Bras Med 1995; 52(4): 299-308.

16. Montalban J., Sumalla J., Fernández J. et al. Empty sella syndrome and pituitary apoplexi. Lancet 1988;

774. 